\title{
Spontaneous 24-h ghrelin secretion pattern in fasting subjects: maintenance of a meal-related pattern
}

\author{
G Natalucci, S Riedl, A Gleiss ${ }^{1}$, T Zidek ${ }^{2}$ and H Frisch \\ Department of Pediatrics, ${ }^{1}$ Core Unit for Medical Statistics and Informatics and ${ }^{2}$ Department of Epidemiology, Cancer Research Institute, \\ Medical University of Vienna, Vienna, Austria
}

(Correspondence should be addressed to S Riedl, Department of Pediatrics, Medical University of Vienna, Währinger Gürtel 18-20, 1090 Vienna, Austria; Email: stefan.riedl@meduniwien.ac.at)

\begin{abstract}
Objective: Ghrelin stimulates GH release and causes weight gain through increased food intake and reduced fat utilization. Ghrelin levels were shown to rise in the preprandial period and decrease shortly after meal consumption, suggesting a role as a possible meal initiator. However, ghrelin secretion in fasting subjects has not yet been studied in detail.

Design: 24-h ghrelin profiles were studied in six healthy volunteers (three females; 25.5 years; body mass index $22.8 \mathrm{~kg} / \mathrm{m}^{2}$ ) and compared with $\mathrm{GH}$, insulin and glucose levels.

Methods: Blood samples were taken every 20 min during a 24-h fasting period and total ghrelin levels were measured by RIA using a polyclonal rabbit antibody. The circadian pattern of ghrelin secretion and pulsatility (Cluster analysis) were evaluated.

Results: An increase and spontaneous decrease in ghrelin were seen at the timepoints of customary meals. Ghrelin was secreted in a pulsatile manner with approximately 8 peaks $/ 24 \mathrm{~h}$. An overall decrease in ghrelin levels was observed during the study period. There was no correlation of ghrelin with $\mathrm{GH}$, insulin or blood glucose levels.

Conclusions: This pilot study indicates that fasting ghrelin profiles display a circadian pattern similar to that described in people eating three times per day. In a fasting condition, GH, insulin and glucose do not appear to be involved in ghrelin regulation. In addition, we found that ghrelin is secreted in a pulsatile pattern. The variation in ghrelin independently of meals in fasting subjects supports previous observations that it is the brain that is primarily involved in the regulation of meal initiation.
\end{abstract}

European Journal of Endocrinology 152 845-850

\section{Introduction}

Ghrelin, a 28-amino-acid peptide with a 3-serine n-octanoylated residue, was purified in 1999 from rat stomach (1) and subsequently cloned in rats and humans. It is an endogenous ligand for the growth hormone (GH) secretagogue receptor, which strongly stimulates GH release (2) but also causes increased appetite and weight gain through increased food intake and reduced fat utilization $(3,4)$. It is synthesized primarily by $\mathrm{X} / \mathrm{A}$-like cells of the oxynthic glands of the gastric mucosa, and in smaller amounts in the hypothalamus (1). The peptide is also expressed in the pituitary, bowel, kidney, pancreas, brain, lung, placenta, ovary and lymphocytes (for review see 5). Ghrelin circulates in human blood in at least two forms: the des-octanoylated form and the less abundant n-octanoylated form. Its biological effect is mainly exerted by the latter. Desoctanoylated and n-octanoylated ghrelin, both constituting total measured ghrelin levels, show a significant correlation, although they vary under fasting or nonfasting conditions (6-8). Circulating ghrelin levels are lower in human obesity (9), whereas in anorectic patients, fasting ghrelin levels are significantly higher than in normal control subjects (10). In addition, human plasma ghrelin levels have been shown to rise in the preprandial and fall in the postprandial period $(11,12)$. It has been concluded that the peptide is a likely player in the regulation system controlling the energy balance of the human organism, being upregulated when the energy balance is negative and downregulated when it is positive $(4,13)$. It is not clear yet whether the postprandial ghrelin decline depends on nutritional factors or on cephalic mechanisms. Moreover, little is known about the role of ghrelin in the regulation of GH during fasting. We studied the course of spontaneous plasma ghrelin concentrations over a 24-h period in healthy, fasting human subjects to characterize the nature of its secretory pattern and compared it with GH, insulin and glucose levels.

\section{Subjects and methods}

Six healthy volunteers (three females) accustomed to eating three meals per day, age (mean \pm S.D.) $25.5 \pm 4.5$ 
years, body mass index (BMI) (mean \pm s.D.) 20.7 \pm $0.1 \mathrm{~kg} / \mathrm{m}^{2}$ (female) $/ 24.9 \pm 1.5 \mathrm{~kg} / \mathrm{m}^{2}$ (male), respectively $\quad-0.41 \pm 0.36$ SDS (female) $/ 1.04 \pm 0.57$ SDS (male) (14), participated in the study.

Exclusion criteria were internal or psychiatric disease, medical treatment, pregnancy or hormonal contraception, use of tobacco products or drug abuse. None of the subjects had undergone gastrointestinal surgery or was on a dietary programme.

Prior approval for the experimental procedure was obtained from the Ethical Committee of the Medical University of Vienna, Austria. The reasons for the investigation and the potential risks were discussed and all subjects gave their written informed consent to participate in the study.

The volunteers were asked to fast from $0000 \mathrm{~h}$ of day 1 until $0900 \mathrm{~h}$ of the following day $(33 \mathrm{~h})$. Subjects were admitted to the Paediatric Department, Medical University Vienna, Austria, at $0730 \mathrm{~h}$ on day 1 and an intravenous cannula was placed in an antecubital vein for blood withdrawal. Peripheral blood samples were collected every $20 \mathrm{~min}$ from $0800 \mathrm{~h}$ on day 1 until $0900 \mathrm{~h}$ on day 2. Dark periods were from $0000 \mathrm{~h}$ on day 2 until $0700 \mathrm{~h}$ on day 2 . The subjects were encouraged to live freely within the constraints of the hospital environment and the sampling protocol. During the fasting period water was allowed ad libitum. There was no possibility to see or smell food in the chosen setting until $0800 \mathrm{~h}$ on day 2, when an unexpected breakfast was served.

All blood samples were transferred to chilled glass disodium EDTA tubes and centrifuged immediately at $4{ }^{\circ} \mathrm{C}$. The plasma samples were frozen and stored at $-35^{\circ} \mathrm{C}$.

Plasma immunoreactive ghrelin was measured in each sample in duplicate $100 \mu \mathrm{l}$ aliquots using commercially available single RIA components (Peninsula Laboratories, Inc., Belmont, CA, USA) comprising a ${ }^{125}$ iodine-labeled bioactive ghrelin tracer and a rabbit polyclonal antibody raised against full-length octanoylated human ghrelin, showing $100 \%$ cross reactivity with des-acyl ghrelin, which does not interfere with any other known gastrointestinal or pancreatic peptide hormones. No extraction procedures were performed.

The lower and upper limits of the assay were 20 and $2000 \mathrm{pg} / \mathrm{ml}$ respectively. The intra- and interassay coefficients of variation were $4.1 \%$ and $12.0 \%$ respectively.

\section{Circadian pattern of ghrelin}

Mean plasma ghrelin levels of the series of 76 samples obtained from each of the six subjects were analysed. To overcome interindividual variation, ghrelin levels were standardized to the mean of the subject, i.e. the respective 24-h mean ghrelin level was subtracted from each individual ghrelin value. A nonparametric regression fit (LOESS fit) was then performed, using an optimal number of $\mathrm{x}$-values (nine timepoints) which were included in the fit. On the basis of these nine values, the $y$-values were weighted according to the distance from the point to the estimate. To find the optimal fit, both the corrected Akaike information criteria (15) and the 'general cross validation-mean square error' (16) were used. Calculations were performed using SAS software version 8.2, 2001 (SAS Institute Inc., Cary, NC, USA). In order to visualize the circadian pattern of all six subjects, a LOESS fit (together with 95\% confidence interval) of the residuals from the patientwise linear regression was calculated using the algorithm provided by the ' $R$ ' software (17).

\section{Linear trend over time}

A linear regression analysis was carried out for each subject's profile as well as for the whole dataset to evaluate the circadian linear trend during the study period.

\section{Pulse analysis of ghrelin and GH}

Fasting ghrelin and GH patterns were analysed by means of computer-based algorithm Cluster analysis (18). A $2 \times 2$ (peak 2, nadir 2) cluster size, the intraassay coefficient of variation, and minimum t-statistics of 2 were used as a stringency criterion for both upstrokes and downstrokes, in order to constrain the false positive rate to $<5 \%$. This setting identified pulses that were consistent with visual appraisal, with the exception of the pulses supposed to exist at the margins of the profiles. The following pulsatility parameters were evaluated: number of peaks representing pulses, interpulse interval determined as the time interval between peaks, peak width calculated in min, representing the time elapsed between the first significant upstroke and first significant downstroke within the overall peak and pulse amplitude defined as the maximum hormone concentration attained in each pulse.

\section{Correlations between ghrelin, GH, insulin and blood glucose}

In order to assess the association between ghrelin and the three other continuous measurement variables, partial Spearman correlation coefficients were calculated for each pair of variables. Partialization was used to account for the variation between patients. The computation of partial correlation coefficients was performed using SAS software version 8.2.

\section{Results}

\section{Circadian pattern of ghrelin}

Smoothed individual 24-h plasma ghrelin levels (LOESS fit) are shown in Fig. 1. A striking increase in plasma ghrelin concentrations could be observed at four timepoints: around $0800 \mathrm{~h}$, between $1200 \mathrm{~h}$ and $1300 \mathrm{~h}$, between $1700 \mathrm{~h}$ and $1900 \mathrm{~h}$ on day 1 , and at the time 


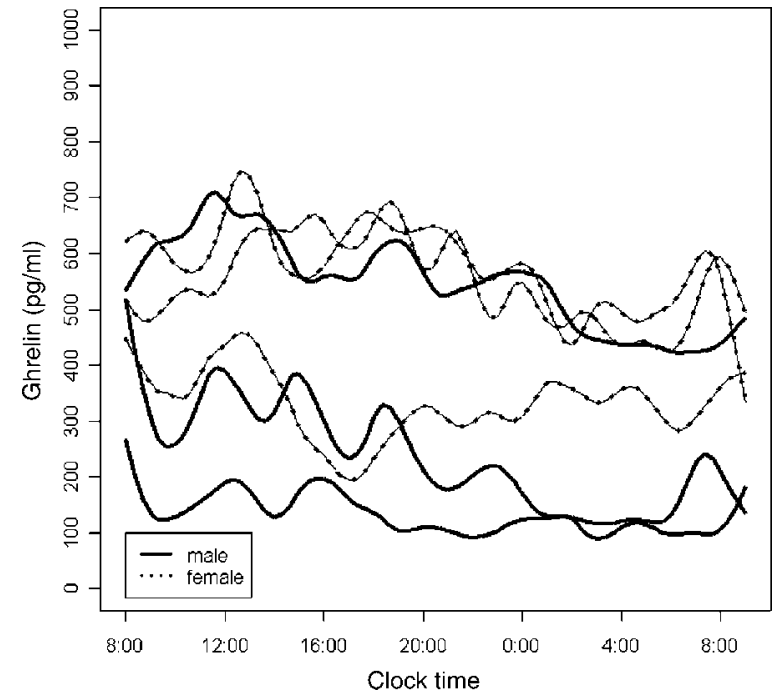

Figure 1 Individual ghrelin profiles from the six subjects during the fasting period (LOESS fit).

of breakfast $(0800 \mathrm{~h})$ on day 2. A smaller peak could be seen around midnight (Fig. 2). Ghrelin levels fell spontaneously after the morning, noon and evening peaks.

Higher ghrelin levels were found in subjects with low BMI (subjects 1, 2, 4) and ghrelin levels tended to be lower in those subjects with higher BMI (subjects 3, 5,6 ) among the subjects of the respective sex (Fig. 1, Table 1).

\section{Linear trend over time}

The diurnal pattern of total ghrelin levels showed an overall decrease during the 24-h fasting period,

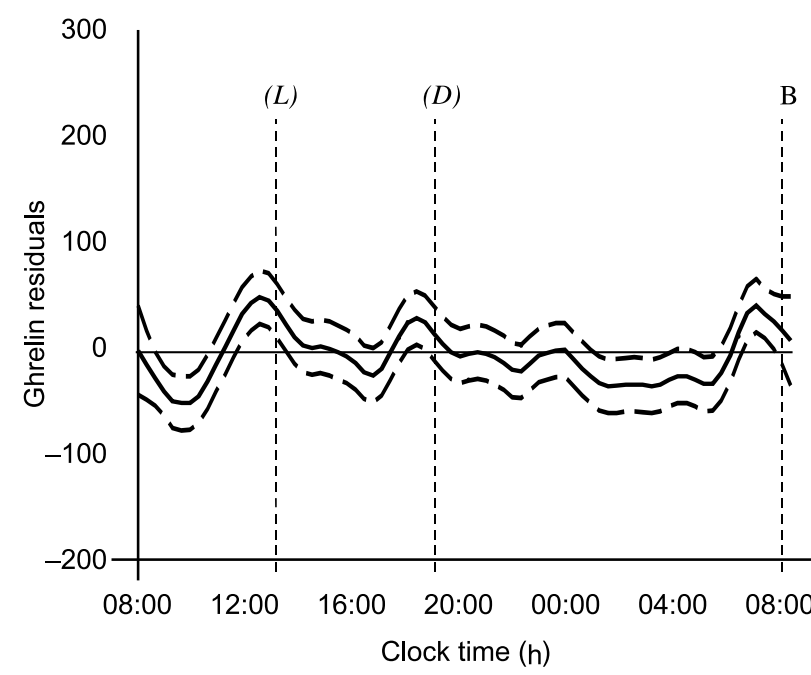

Figure 2 Circadian ghrelin pattern computed as LOESS fit of the residuals from the patientwise linear time trends (solid line) with upper and lower 95\% confidence intervals of the LOESS fit

(broken lines). Dotted vertical lines indicate customary meal times $((L)$, lunch; $(D)$, dinner). At $0800 \mathrm{~h}$ on day 2 the subjects received an unexpected breakfast (B). gradually falling to a trough between $0000 \mathrm{~h}$ and $0700 \mathrm{~h}$ on day 2, until the breakfast surge began (Fig. 3). Linear regression demonstrated a downward slope for each subject which was statistically significant (uncorrected $P<0.05$ ) in five subjects.

\section{Pulse analysis of ghrelin}

Using the Cluster program, the following peak characteristics were seen: peak number 8.3 (range $7-10$ ), interval between peaks $148 \pm 54 \mathrm{~min}$, peak width $115 \pm 53 \mathrm{~min}$ and pulse amplitude $509 \pm 115 \mathrm{pg} / \mathrm{ml}$. Detailed results of all 6 subjects' profiles are presented in Table 1. Two representative profiles are shown in Fig. 4. No association between ghrelin and $\mathrm{GH}$ regarding the times of peak occurrence could be found.

\section{Correlations between ghrelin, GH, insulin and blood glucose}

The investigation of potential pairwise association between ghrelin, $\mathrm{GH}$, insulin and glucose revealed only a weak partial correlation between $\mathrm{GH}$ and insulin $(\mathrm{R}=-0.381)$ and between blood glucose and insulin $(\mathrm{R}=0.313)$, the latter showing non relevant variations within the normal basal range under fasting conditions. All other correlation coefficients had absolute values below 0.170. The apparent coincidence of peaks in the LOESS fits of ghrelin followed by $\mathrm{GH}$ (Fig. 5) was not captured by the extremely weak partial correlation coefficient of -0.08 . Partialisation for postprandial phases or darkness/light phases did not show any relevant influence on the results. Similarly, considering lagged ghrelin values (lags of one, two and three periods, corresponding to 20,40 and $60 \mathrm{~min}$ respectively) had no effect on the results.

\section{Discussion}

There is continuous debate as to whether ghrelin secretion is regulated via central (i.e. hypothalamic) or peripheral (i.e. nutrition-related/gastric) mechanisms. The rise in circulating ghrelin levels before a meal indicates its role as a hunger signal to initiate food consumption $(11,19)$. This observation is supported by experimental studies showing that ghrelin administration in rodents rapidly increases food intake $(20,21)$. Within $1 \mathrm{~h}$ of food consumption, ghrelin fell to trough levels, and this meal-associated rise and fall of ghrelin resulted in a characteristic secretion pattern in non-fasting subjects (11).

Interestingly, the 24-h ghrelin secretion pattern in our six fasting subjects demonstrated a similar course, with an increase at customary mealtimes and a spontaneous decrease after approximately $2 \mathrm{~h}$ without food consumption (Figs 1-3). 
Table 1 Subjects' characteristics and results from Cluster analysis of ghrelin levels during the 24-h fasting period.

\begin{tabular}{lccccccc}
\hline Subject & Sex & $\begin{array}{c}\text { Age } \\
\text { (years) }\end{array}$ & $\begin{array}{c}\text { BMI } \\
\left(\mathrm{kg} / \mathrm{m}^{2}\right)[\mathrm{SDS}]\end{array}$ & $\begin{array}{c}\text { No. of } \\
\text { peaks }\end{array}$ & $\begin{array}{c}\text { Mean interval between } \\
\text { peaks }(\mathrm{min})\end{array}$ & $\begin{array}{c}\text { Mean peak width } \\
(\mathrm{min})\end{array}$ & $\begin{array}{c}\text { Mean pulse amplitude } \\
(\mathrm{pg} / \mathrm{ml})\end{array}$ \\
\hline 1 & $\mathrm{~F}$ & 28.6 & $20.0[-0.67]$ & 8 & $157.1 \pm 57.1$ & $117.5 \pm 16.7$ & $715.2 \pm 135.4$ \\
2 & $\mathrm{~F}$ & 21.9 & $20.3[-0.56]$ & 7 & $176.7 \pm 36.7$ & $125.7 \pm 59.7$ & $707.1 \pm 83.5$ \\
3 & $\mathrm{~F}$ & 19.0 & $21.8[0]$ & 10 & $122.2 \pm 56.1$ & $92.0 \pm 62.7$ & $411.8 \pm 64.7$ \\
4 & $\mathrm{M}$ & 30.0 & $23.8[0.62]$ & 8 & $148.6 \pm 54.0$ & $130.0 \pm 51.3$ & $686.0 \pm 123.4$ \\
5 & $\mathrm{M}$ & 25.0 & $24.3[0.81]$ & 9 & $132.5 \pm 36.9$ & $111.1 \pm 60.9$ & $185.8 \pm 51.0$ \\
6 & $\mathrm{M}$ & 28.6 & $26.6[1.68]$ & 8 & $151.4 \pm 73.8$ & $115.0 \pm 53.2$ & $348.9 \pm 179.2$ \\
\hline
\end{tabular}

SDS, standard deviation score.

Regarding the ghrelin rise, a priming effect of customary food consumption on ghrelin secretion is supported by an experimental study in sheep, showing a change in the ghrelin secretion pattern produced by different feeding regimes (22). By analogy, serum insulin levels increase just before an expected meal. This 'cephalic phase' of insulin secretion could be provoked as a Pavlovian reflex, even without food presentation (23). It might be concluded that the secretion of ghrelin is subjected to processes of classical conditioning, as is well known from other vegetative functions.

The regular spontaneous ghrelin decrease after its rise at customary meal times was surprising. Studying the course of ghrelin secretion in non-fasting subjects, it has been speculated that the postprandial fall in ghrelin is actually mediated by the ingested nutrients (11). Regarding the histological structure of the oxynthic mucosa, ghrelin-secreting cells have no direct contact with the gastric lumen. Therefore, it would be more likely that physical or chemical stimuli from the basolateral membrane influence ghrelin secretion rather than direct contact of ingested nutritional products with gastric mucosa $(24,25)$. Moreover, it has been

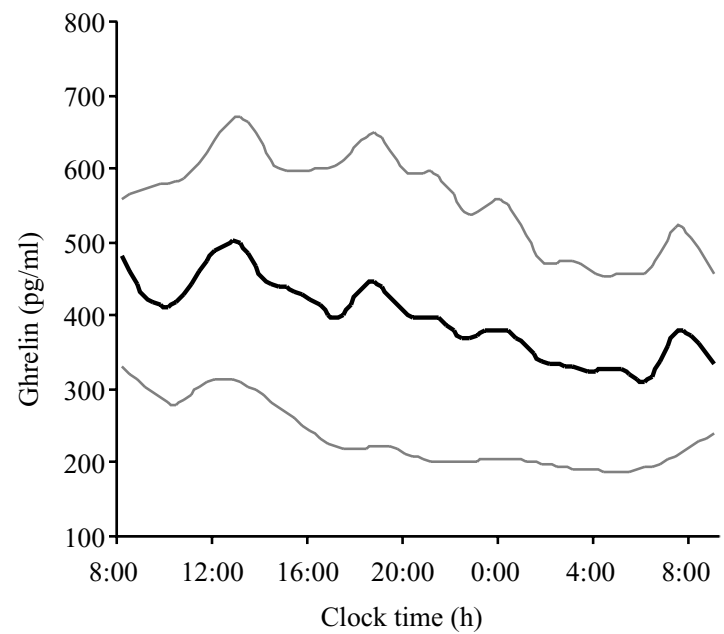

Figure 3 Average total plasma ghrelin profile from all 6 subjects (central thick line), and average plasma ghrelin profile from three high level and from three low level subjects (upper and lower lines respectively). Note the overall decrease in ghrelin levels during the 24-h fasting period. shown that water ingestion per se or the resulting gastric distension had no effect on circulating ghrelin levels (26). The influence of meal-related changes of insulin or glucose on the postprandial decrease of ghrelin is not entirely clear. Several studies have shown, although not consistently, a decrease in plasma ghrelin levels in hyperglycaemic or hyperinsulinaemic conditions (27-31). Postprandial somatostatin secretion might also exert an inhibitory effect on ghrelin secretion (32-34). However, in our fasting individuals a spontaneous ghrelin decrease was observed which occurred later compared with non-fasting subjects and without a marked change in insulin or glucose levels. This indicates mechanisms at a neuronal level which are independent of gastric stimuli.

We found a significant decrease in ghrelin levels over a 24-h period (Fig. 3) which was not observed in nonfasting subjects (11). In accordance with this, individual hunger perception, as rated on a scale from 1 to 10 by the probands, decreased during the second half of the observation period (data not shown).

The spontaneous secretion pattern of ghrelin as analysed by the Cluster algorithm demonstrated a characteristic pulsatility with a frequency of $8.3 \pm 0.9$ pulses over a $24-\mathrm{h}$ period. This further indicates that neuronal rather than gastrointestinal signals might be operative in the modulation of ghrelin secretion. Accordingly,

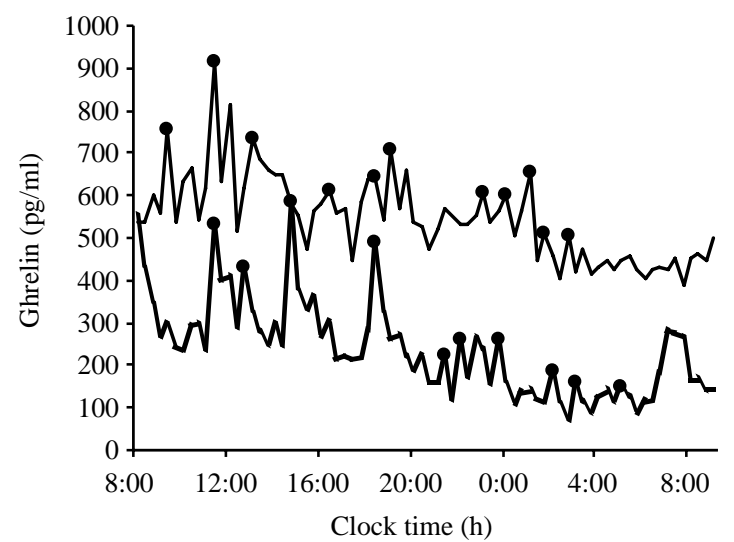

Figure 4 Characteristic 24-h fasting plasma ghrelin profiles from two subjects. $(\bullet)$ represent pulses as identified by Cluster analysis. 


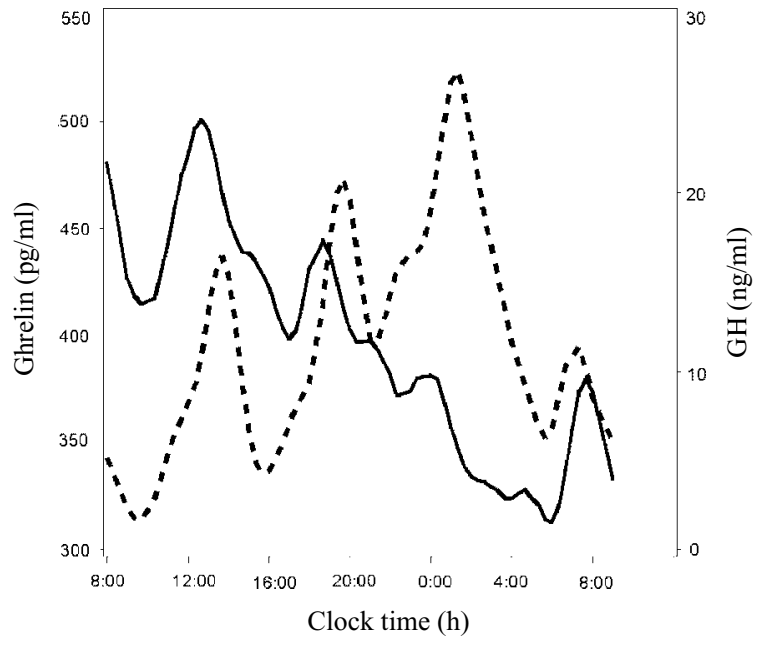

Figure 5 Circadian ghrelin and GH profiles from all 6 subjects during the fasting period (LOESS fit). Solid line, ghrelin; dashed line, $\mathrm{GH}$.

rats showed a higher ghrelin pulse frequency during $3 \mathrm{~h}$ of fasting than in a fed state (35).

We found considerable interindividual variation in plasma ghrelin levels among the six subjects (Fig. 1). Interestingly, higher profiles were found in the two females with the lower BMIs and in the male with the lowest BMI as compared with the other males. These data are in agreement with other observations in adults and children demonstrating the influence of body constitution and nutritional status on circulating ghrelin levels $(9,10,26)$ and possibly support the observation of sexual dimorphism of circulating ghrelin concentrations, with higher levels found in females $(32,36)$.

It is well known that ghrelin administration will stimulate GH secretion $(2,37)$. Furthermore, a synchronicity of ghrelin and $\mathrm{GH}$ was seen during various nutritional regimes (32). However, under fasting conditions we did not find any correlation between these two hormones. Both ghrelin and GH were secreted in a pulsatile manner and we found a similar pulse frequency, but the pattern and timing of pulses were not concordant. This is in agreement with the observation of the lack of correlation between ghrelin and GH circulating levels in male adult rats (38). It seems that ghrelin is not involved in the regulation of GH pulsatility under basal conditions.

In conclusion, our investigation on ghrelin plasma levels in six fasting subjects revealed a characteristic diurnal course with spontaneous rises and declines at customary mealtimes, an overall decrease in ghrelin levels during the 24-h fasting period, and a pulsatile secretion pattern, but these pulses were not related to GH, insulin or blood glucose. Our data indicate that ghrelin, although mainly secreted by the stomach and regulated by caloric intake, is basically under cephalic control.

\section{Acknowledgements}

We acknowledge Susanne Sagmeister's expert technical assistance and Peter Nowotny's help in establishing the ghrelin assay. Parts of this study were presented at the 42nd Annual Meeting of the European Society for Paediatric Endocrinology in Ljubljana, Slovenia.

\section{References}

1 Kojima M, Hosoda H, Date Y, Nakazato M, Matsuo H \& Kangawa K. Ghrelin is a growth hormone-releasing acylated peptide from stomach. Nature $1999 \mathbf{4 0 2} 656-660$.

2 Takaya K, Ariyasu H, Kanamoto N, Iwakura H, Yoshimoto A, Harada M, Mori K, Komatsu Y, Usui T, Shimatsu A, Ogawa Y, Hosoda K, Akamizu T, Kojima M, Kangawa K \& Nakao K. Ghrelin strongly stimulates growth hormone $(\mathrm{GH})$ release in humans. Journal of Clinical Endocrinology and Metabolism $2000 \mathbf{8 5}$ 4908-4911.

3 Tschöp M, Smiley DL \& Heiman ML. Ghrelin induces adiposity in rodents. Nature $2000 \mathbf{4 0 7} 908-913$.

4 Shintani M, Ogawa Y, Ebihara K, Aizawa-Abe M, Miyanaga F, Takaya K, Hayashi T, Inoue G, Hosoda K, Kojima M, Kangawa K \& Nakao K. Ghrelin, an endogenous growth hormone secretagogue, is a novel orexigenic peptide that antagonizes leptin action through the activation of the hypothalamic neuropeptide Y/Y1 receptor pathway. Diabetes $200150227-232$.

5 Gualillo O, Lago F, Gómez-Reino J, Casanueva FF \& Dieguez C. Ghrelin, a widespread hormone: insights into molecular and cellular regulation of its expression and mechanism of action. FEBS Letters $2003 \mathbf{5 5 2} 105-109$.

6 Toshinai K, Mondal MS, Nakasato M, Date Y, Murakami N, Kojima M, Kangawa K \& Matsukura S. Upregulation of ghrelin expression in the stomach upon fasting, insulin-induced hyperglycemia, and leptin administration. Biochemical and Biophysical Research Communications 2001281 1220-1225.

7 Murakami N, Hayashida N, Kuroiwa T, Nakahara K, Ida T, Mondal MS, Nakazato M, Kojima M \& Kangawa K. Role for central ghrelin in food intake and secretion profile of stomach ghrelin in rats. Journal of Endocrinology 2002174 283-288.

8 Marzullo P, Verti B, Savia G, Walker GE, Guzzaloni G, Tagliaferro M, Di Blasio A \& Liuzzi A. The relationship between active ghrelin levels and human obesity involves alterations in resting energy expenditure. Journal of Clinical Endocrinology and Metabolism 200489 936-939.

9 Tschöp M, Weyer C, Tataranni PA, Devanarayan V, Ravussin E \& Heiman ML. Circulating ghrelin levels are decreased in human obesity. Diabetes $200150707-709$.

10 Otto B, Cunts U, Fruehauf E, Wawarta R, Folwaczny C, Riepl RL, Heiman ML, Lehnert P, Fichter M \& Tschöp M. Weight gain decreases elevated plasma ghrelin concentration of patients with anorexia nervosa. European Journal of Endocrinology 2001 145 R $5-\mathrm{R} 9$.

11 Cummings DE, Purnell JQ, Frayo RS, Schmidova K, Wisse BW \& Weigle DS. A preprandial rise in plasma ghrelin levels suggests a role in meal initiation in humans. Diabetes $2001 \mathbf{5 0}$ 1714-1719.

12 Tschöp M, Wawarta R, Riepl RL, Friedrich S, Bidlingmaier M, Landgraf $\mathrm{R} \&$ Folwaczni C. Post-prandial decrease of circulating human ghrelin levels. Journal of Endocrinological Investigation 200124 RC19-RC21.

13 Horvath TL, Diano S, Sotonyi P, Heiman M \& Tschöp M. Minireview: Ghrelin and the regulation of energy balance - a hypothalamic perspective. Endocrinology $20011424163-4169$.

14 He Q, Albertsson-Wikland K \& Karlberg J. Population-based body mass index reference values from Göteborg, Sweden: birth to 18 years of age. Acta Paediatrica $200089582-592$. 
15 Hurvich CM \& Simonoff JS. Smoothing parameter selection in non parametric regression using an improved Akaike information criterion. Journal of the Royal Statistical Society B $199860271-293$.

16 Craven P \& Wahba G. Smoothing noisy data with spline functions. Numerical Mathematics 197931 377-403.

17 Cleveland WS \& Grosse E. Computational methods for local regression. Statistics and Computing 19911 47-62.

18 Veldhuis JD \& Johnson ML. Cluster analysis: a simple, versatile, and robust algorithm for endocrine pulse detection. American Journal of Physiology 1986250 E486-E493.

19 Broglio F, Gottero C, Arvat E \& Ghigo E. Endocrine and non-endocrine actions of ghrelin. Hormone Research 200359 109-117.

20 Wren AM, Small CJ, Ward HL, Murphy KG, Dakin CL, Taheri S, Kennedy AR, Roberts GH, Morgan DGA, Ghatei MA \& Bloom SR. The novel hypothalamic peptide ghrelin stimulates food intake and growth hormone secretion. Endocrinology 2001 $1414325-4328$

21 Nakazato M, Murakami N, Date Y, Kojima M, Matsuo H, Kangawa K \& Matsukura S. A role for ghrelin in the central regulation of feeding. Nature $2001 \mathbf{4 0 9} 194-198$.

22 Sugino T, Yamaura J, Yamagishi M, Omura A, Hayashi R, Kurose Y, Kojima M, Kangawa K, Hasegawa Y \& Terashima Y A transient surge of ghrelin secretion before feeding is modified by different feeding regimens in sheep. Biochemical and Biophysical Research Communications 2002298 785-788.

23 Louis-Sylvestre J. The cephalic phase of insulin secretion. Diabetes Metabolism 198713 63-73.

24 Date Y, Kojima M, Hosoda H, Sawaguchi A, Mondal MS, Suganoma T, Matsukura S, Kangawa K \& Nakazato M. Ghrelin, a novel growth hormone-releasing acylated peptide, is synthesized in a distinct endocrine cell type in the gastrointestinal tracts of rats and humans. Endocrinology $20001414255-4261$

25 Dornonville de la Court C, Bjorkqvist M, Sandvick AK, Bakke I, Zaho CM, Chen D \& Håkanson R. A-like cells in the rat stomach contain ghrelin and do not operate under gastrin control. Regulatory Peptides 200199 141-150.

26 Shiiya T, Nakazato M, Mizuta M, Date Y, Mondal MS, Tanaka M, Nozoe S, Hosoda H, Kangawa K \& Matsukura S. Plasma ghrelin levels in lean and obese humans and the effect of glucose on ghrelin secretion. Journal of Clinical Endocrinology and Metabolism 2002 87 240-244.

27 Caixàs A, Bashore C, Nash W, Pi-Sunyer F \& Laferrère B. Insulin, unlike food intake, does not suppress ghrelin in human subjects. Journal of Clinical Endocrinology and Metabolism $2002 \quad 87$ 1902-1906.

28 Mohlig M, Spranger J, Otto B, Ristow M, Tschöp M \& Pfeiffer AF. Euglycemic hyperinsulinemia, but not lipid infusion, decreases circulating ghrelin levels in humans. Journal of Endocrinological Investigation 200225 RC36-RC38.
29 Nakagawa E, Nagaya N, Okumura H, Enomoto M, Oya H, Ono F, Hosoda H, Kojima M \& Kangawa K. Hyperglycemia suppress the secretion of ghrelin, a novel growth hormone-releasing peptide: response to the intravenous and oral administration of glucose. Clinical Science 2002103 325-328.

30 Flanagan DE, Evans ML, Monsod TP, Rife F, Heptulla RA, Tamborlane WV \& Sherwin RS. The influence of insulin on circulating ghrelin. American Journal of Physiology - Endocrinology and Metabolism 2003284 E313-E316.

31 Murdolo G, Lucidi P, Di Loreto C, Parlanti N, De Cicco A, Fatone C, Fanelli CG, Bolli GB, Santeusiano F \& De Feo P. Insulin is required for prandial ghrelin suppression in humans. Diabetes $2003 \mathbf{5 2}$ 2923-2927.

32 Barkan AL, Dimaraki EV, Jessup SK, Symons KV, Ermolenko M \& Jaffe CA. Ghrelin secretion in humans is sexually dimorphic, suppressed by somatostatin, and not affected by the ambient growth hormone levels. Journal of Clinical Endocrinology and Metabolism $2003882180-2184$.

33 Schaller G, Schmidt A, Pleiner J, Woloszczuk W, Woltz M \& Luger A. Plasma ghrelin concentrations are not regulated by glucose or insulin. Diabetes 200352 16-20.

34 Shimada M, Date Y, Mondal MS, Toshinai K, Shimbara T, Fukunaga K, Murakami N, Miyazato M, Kangawa K, Yoshimatsu H, Matsuo H \& Nakazato M. Somatostatin suppresses ghrelin secretion from the rat stomach. Biochemical and Biophysical Research Communications 2003302 520-525.

35 Bagnasco M, Kalra PS \& Kalra SP. Ghrelin and leptin pulse discharge in fed and fasted rats. Endocrinology 2002143 726-729.

36 Greenman Y, Golani N, Gilad S, Yaron M, Limor R \& Stern N. Ghrelin secretion is modulated in a nutrient- and gender-specific manner. Clinical Endocrinology $200460382-388$.

37 Arvat E, Maccario M, Di Vito L, Broglio F, Benso A, Gottero C, Papotti M, Muccioli G, Diéguez C, Casanueva FF, Deghenghi R, Camanni F \& Ghigo E. Endocrine activities of ghrelin, a natural growth hormone secretagogue (GHS), in humans: comparison and interactions with hexarelin, a non natural peptidyl GHS, and GH-releasing hormone. Journal of Clinical Endocrinology and Metabolism 200186 1169-1174.

38 Tolle V, Bassant MH, Zizzari P, Poindessous-Jazat F, Tomasetto C, Epelbaum J \& Bluet-Pajot MT. Ultradian rhythmicity of ghrelin secretion in relation with $\mathrm{GH}$, feeding behavior, and sleep-wake patterns in rats. Endocrinology 2002143 1353-1361.

Received 10 December 2004

Accepted 3 March 2005 